\title{
ジアンチピリルメタンによるアルミニゥムおよび その合金中のチタンの吸光光度定量法
}

\author{
秋 山和 一** 小林幸 雄**
}

Spectrophotometric determination of titanium in aluminum and its alloys with diantipyrylmethane*

UDC $543.4: 669.715: 546.821$

AKIYAMA Kazuichi** $\cdot$ KOBAYASHI Yukio**

Diantipyrylmethane has been found as a selective reagent for forming a yellow complex with titanium in hydrochloric acid. Slow developing of color appeared, but fully developed color solution was stable for a long period. The color developing depended on temperature, addition amount of the reagent, and concentration of hydrochloric acid. The present method would be applied to the determination of titanium in various aluminum alloys with almost no effects of co-existent elements. The recommended procedure was as follows.

The aluminum alloy was dissolved in dil. hydrochloric acid and insoluble matter was filtered off. Then, the solution was diluted to a known volume. An aliquot of the solution was transferred to a volumetric flask, into which ascorbic acid was added and allowed to settle. Then, diantipyrylmethane solution was added to it and it was allowed to stand for $1 \mathrm{hr}$. Optical density of the solution was measured at $390 \mathrm{~m} \mu$ by comparing it with a control solution prepared in the same way, but containing no diantipyrylmethane, and titanium was determined by the calibration curve.

(Received Mar. 20, 1967)

\section{1. 緒言}

チタンの吸光光度定量法にはクロモトロープ酸法1), タイロン法 ${ }^{2)}$, アリザリン $\mathrm{S}$ 法 $^{3)}$, スルホサリチル酸法 ${ }^{4}$, 過酸化水素法などがあるが, 共存元素の影響, 試薬の不安 定, 液温の影響, 低感度など，いずれかの欠点があり， 特に高純度アルミニウムおよびアルミニウム合金中のチ タンの定量には難点がある。筆者うは, 精製アルミニウ ムからアルミニウム合金まで広範囲に適用できる方法を 求めて, 種々検討の結果, ジアンチピリルメタン (DAM) 法が最適であることを確め， Polyak ${ }^{5)}$ および Jefery ${ }^{6)} ら$ の方法を検討し，さらに改良して，アルミニウムおよび その合金中のチタンの定量に応用し, 本定量法を確立し た。

\section{2. 定 量 法}

\section{1 試薬}

塩 酸 $(1+1)$

塩化ニツケル溶液 : 純金属ニツケル $0.1 \mathrm{~g}$ を少量の硝
酸に溶解し, 蒸発乾固したのち塩酸に溶解し, 再び烝発 乾固し，これを塩酸に溶解し，水で $100 \mathrm{ml}$ にうすめる。 アスコルビン酸溶液 : アスコルビン酸 $10 \mathrm{~g}$ を水に溶解 し $100 \mathrm{ml}$ とする。本液は暗所に貯える。あまり着色し たものは使用しない方がよい。

ジアンチピリルメタン 1 \%溶液 : ジアンチピリルメタ ン $1 \mathrm{~g}$ を稀塩酸 $(0.5 \mathrm{~N})$ に溶解し, 稀塩酸 $(0.5 \mathrm{~N})$ で $100 \mathrm{ml}$ とする。本液は暗所に貯える。なお本液は使用 のつど調製することが望ましい。

チタン標準溶液: 灼熱後冷却した純酸化チタン 0.200 $\mathrm{g}$ を正確に白金ルツボにはかりとり，ピロ硫酸カリウム $5 \mathrm{~g}$ 学加え加熱溶融する。冷後稀硫酸 $5 \%(\mathrm{v} / \mathrm{v} \%)$ を みたしたビーカー中に浸漬し加熱溶解する。冷後メスフ ラスコ（（ll$）$ に移し，稀硫酸（5％) で正確に標線ま でらすめる。本液 $1 \mathrm{~m} l$ は $0.12 \mathrm{mg}$ のチタンを含有する。 なおこれを原液とし，使用のつど10倍にうすめて使用す る。

\section{2 要旨}

試料を塩酸で分解しこしわけ, 冷後定容とする。所要

* 分析化学第14年次会 (1965年) で発表した。

** 昭和電工株式会社中央研究所 Showa Denko Co., Ltd. Central Research Laboratory. 
量を分取し，アスコルビン酸溶液を加え還元したのち， ジアンチピリルメタン溶液を加え, 定容とし完全発色す るまで放置する。吸光度を測りチタン含有率を求める。

\section{3 分析操作}

試料*を正確にビーカー $(300 \mathrm{ml})$ にはかりとり, 時計 ザラでおおい，塩酸 $(1+1) 25 \mathrm{ml}$ を加え**，反応が 静かになつてから, 過酸化水素水（3\%） $5 \mathrm{ml}$ を加え 加熱し, 試料を完全に分解したのち軽く煮沸し, 過酸化 水素を分解する。

残サがあればこしわけ温水で洗う***。冷後ろ液をメ スフラスコ $(200 \mathrm{ml})$ に移し, 水で正確に標線までうす める。 $20 \mathrm{~m} l$ をメスフラスコ $(50 \mathrm{~m} l)$ に分取し，アスコ ルビン酸溶液 $2.5 \mathrm{~m} l$ を加え, 15分間放置する。これにジ アンチピリルメタン $1 \%$ 溶液 $20 \mathrm{~m} l^{* * * *}$ を加え, 水で正確

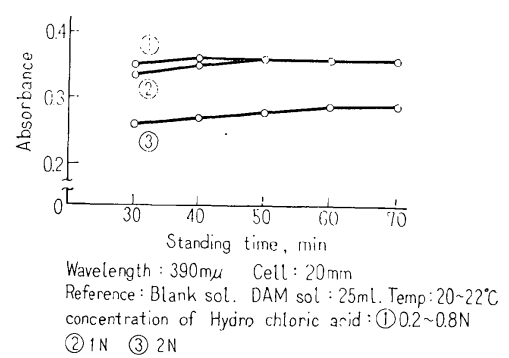

Fig. 1 Effect of concentration of Hydrochloric acid (Ti $0.06 \mathrm{mg} / 100 \mathrm{ml}$ ).

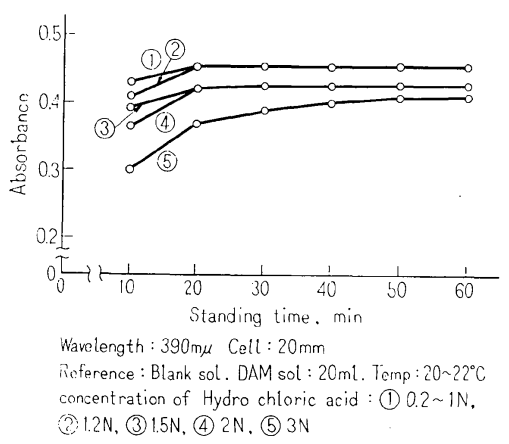

Fig. 2 Effect of concentration of Hydrochloric acid (Ti $0.036 \mathrm{mg} / 50 \mathrm{ml}$ ).

* チタン0.005 mg以上分取できるように試料をはかりとる。 精製アルミニウム等チタン $0.001 \%$ 以下のときは, 試料 $1 \mathrm{~g}$ をは かりとり, 液量を $100 \mathrm{ml}$ とし, これより $25 \mathrm{ml}$ を分取して発色し たのち， $5 \mathrm{~cm}$ セルを用いて測定することが望ましい。

** 精製アルミニウムなど溶解困難な試料は, 塩化ニツケル 溶液約 $1 \mathrm{ml}$ を加え, 溶解を早める。

*** Ti-Boride を含む試料の場合は, 残サ中にチタンが残留 するので。これを灰化後ピロ硫酸カリウム $1 \mathrm{~g}$ を用、溶融し, 泠 後口液に溶解し可検溶液とする。

**** ジアンチピリルメタンの添加量が少ないと発色が遅れ る。最終液量 $100 \mathrm{~m} l$ の場合は $25 \sim 30 \mathrm{~m} l, 25 \mathrm{~m} l$ の場合は $10 \mathrm{ml}$ 加 えることが必要である。

***** 液温が $20^{\circ} \mathrm{C}$ 以下にあると発色がおくれてくる。
に標線までうすめよくふりまぜ， $20 \sim 30^{\circ} \mathrm{C}$ の液温で約 1 $\mathrm{hr}$ 放置後*****, 可検溶液の一部を吸収セルにとり，ジア ンチピリルメタン溶液のみを加えない可検溶液を対照液 として, $390 \mathrm{~m} \mu$ 付近の波長で吸光度を測り, あらかじめ 作成してある検量線からチタン含有率を求める******。

\section{3. 定量条件の検討}

\section{1 塩酸濃度の影響}

Polyak $^{5)}$ は, 最終液量 $100 \mathrm{ml}$ の場合塩酸濃度 $1 \sim 4$ $\mathrm{N}$ とし, ジアンチピリルメタン $1 \%$ 溶液 $25 \mathrm{ml}$ を加える と, 45分間以内に完全に発色したと報告しているが， Jefery ${ }^{6)}$ らはこの条件では完全発色するまで $3 \mathrm{hr}$ を要 したと報告している。筆者らは，Polyak らの条件で最 終液量 $50 \mathrm{ml}$ とした場合について実験を行なつた。Fig. 1 は $100 \mathrm{ml}$ の場合で, 塩酸濃度 $0.2 \sim 1 \mathrm{~N}$ では50分間放 置すれば完全に発色するが，これより濃度が濃くなるに したがつて発色がおくれてくる。Fig. 2 は液量 $50 \mathrm{ml}$ の 場合であるが，0.2 1.2Nでは30分閒放置すれば完全に 発色し，これより濃度が䟴くなるにしたがつて発色がお くれてくる。な扩鈴木ら ${ }^{9)}$ も $1 \mathrm{~N}$ 以下がよいと報告して いる。

\section{2 ジアンチピリルメタン添加量}

Polyak ら ${ }^{5) 8)}$ によるとDAM $1 \%$ 溶液の添加量は, 25 $\sim 30 \mathrm{~m} l$ 添加している。その添加量による 経時変化をみ るため, 最終液量 $50 \mathrm{~m} l$ と $100 \mathrm{~m} l$ とについて実験を行な つた。Fig. 3 は $100 \mathrm{ml}$ の場合で, 25〜30 $\mathrm{ml}$ 添加すれ ば60分以内に完全発色するが，それ以下の添加量では発 色がおくれてくる。Fig. 4 は $50 \mathrm{ml}$ の場合で, $20 \mathrm{ml}$ 以 上添加すれば30分位で完全に発色するが，これ以下の添

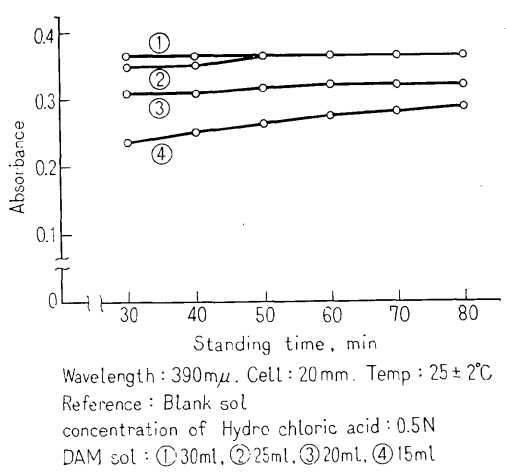

Fig. 3 Effect of amount of DAM (Ti $0.06 \mathrm{mg} / 100$ $\mathrm{m} l)$.

****** 検量線の作り方：標準チタン溶液の各所要量(最終液 量 $50 \mathrm{~m} l$ の場合 $\mathrm{Ti} 0.01 \sim 0.04 \mathrm{mg}$ ）をメスフラスコにとり，ア スコルビン酸 $10 \%$ 溶液 $2.5 \mathrm{ml}$ を加え15分間放置後, DAM $1 \%$ 溶液 (最終液量 $100 \mathrm{ml}$ で $25 \mathrm{~m} l, 30 \mathrm{~m} l, 50 \mathrm{~m} l$ で $20 \mathrm{~m} l, 25 \mathrm{ml}$ で $10 \mathrm{~m} l)$ を加え, 最終塩酸濃度約 $0.5 \mathrm{~N}$ になるよう塩酸を加え, 以下本文操作に準じ操作し吸光度を測定し, 吸光度とチタン量 との関倸線を作り検量線を作成する。 
加量では60分間放置しても完全に発色しない。錯体の発 色を早めるためには DAM $1 \%$ 溶液25〜30 $\mathrm{ml} / 100 \mathrm{ml}$, $20 \mathrm{~m} l / 50 \mathrm{~m} l, 10 \mathrm{~m} l / 25 \mathrm{~m} l$ を添加する必要がある。

\section{3 液温の影響}

錯体の生成におよぼす液温の影響については報告がほ

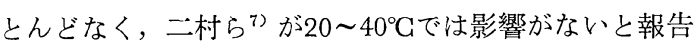
しているのみである。筆者らは液温の影響をみるため 10 $\sim 30^{\circ} \mathrm{G}$ と変化し，その影響による経時変化を求めた。

Fig. 5 に示すごとく, $20^{\circ} \mathrm{G}$ 以上の液温では60分間放置す れば完全に発色しその後安定であるが，これ以下になる としだいに発色がおくれてくる。したがつて $20^{\circ} \mathrm{G}$ 以上の 液温で発色することが必要である。また前述のごとく塩 酸濃度は $1 \mathrm{~N}$ 以下, DAM 量は $50 \mathrm{~m} l$ の場合 $20 \mathrm{~m} l$ 加え, $20^{\circ} \mathrm{G}$ 以上の液温で 60 分閒放置することが望ましい。な お $40 \sim 90^{\circ} \mathrm{G}$ に加温すれば幾分試薬による着色がみられる が，可検，空試験両液を同一条件で加温すればその影響 なく定量することができる。

\section{4 吸収特性}

$\mathrm{DAM}$ とチタンとは，380〜390m $\mu$ に極大吸収をもつ た黄金色の錯体，たとえば $\left[\mathrm{Ti}(\mathrm{DAM})_{3}\right]^{4+}$ を作ると

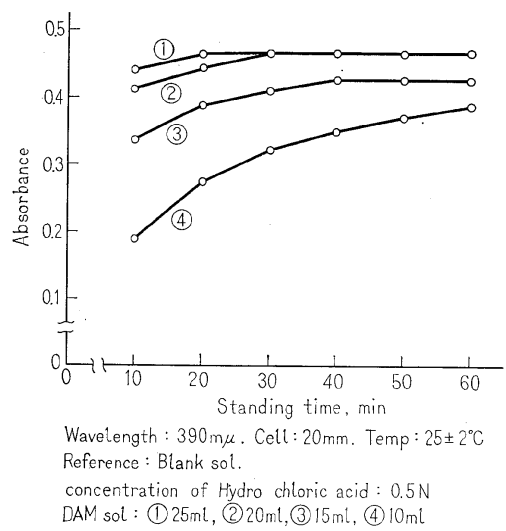

Fig. 4 Effect of amount of DAM (Ti_0.036 mg/50 $\mathrm{m} l)$

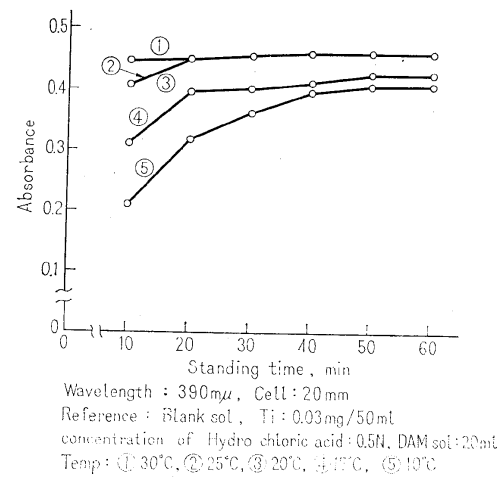

Fig. 5 Effect of reaction temperature.
Podchainova ら ${ }^{10)}$ は報告している。筆者らが自記分光 光度計を用い測定した吸収曲線は Fig. 6 の通りで, 最 大吸収は $390 \mathrm{~m} \mu$ 付近にある。なお空試験溶液はほとん ど吸収を認めなかつた。

\section{5 錯体の安定性と DAM 溶液について}

Ti-DAM 錯体は非常に安定で， Polyak ${ }^{5)}$ ，Jefery ${ }^{6)}$ ら は数か月間安定であると報告している。筆者らは $70 \mathrm{hr}$ まで実験を行なったが Fig.7 に示すごとく安定であつ た。全文献が DAM の稀硫酸溶液を用いているが，筆 者らは稀塩酸溶液がむしろ安定なのでこれを使用した。 DAM 溶液は光によって徐々に分解するので暗所に貯え る必要がある。使用のつど調製した方がよい。またこれ を安定にするため，Jefery ら ${ }^{6}$ はアスコルビン酸を加え ているが，むしろアスコルビン酸自身の分解により着色 しやすい。

\section{6 検量線と各方法との比較}

Fig. 8 は液量 $50 \mathrm{ml}$ の場合の検量線，Fig. 9 は液量 100 $\mathrm{m} l$ の場合の各方法の検量線を示す。クロモトロープ酸 法は PH 3.0 タイロン法は PH 4.5 で発色したものであ る。アリザリン S 法, 過酸化水素法は JIS アルミニウム 合金中のチタン分析方法（JIS H 1359-1963）によるも のである。Fig. 9 に示すごとく本法はタイロン法と同じ 感度で, 過酸化水素法 $(\varepsilon=740)$ の約20倍の感度であ る。また後述するごとくほとんど共存イオンの影響をら けず容易に定量することができる。なお，鉄（0-フェナ ントロリン法）と同じ可検溶液を用いて定量できる。

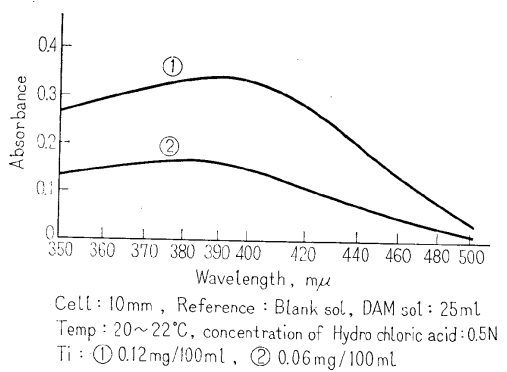

Fig. 6 Absorption spectrum of Ti-DAM complex.

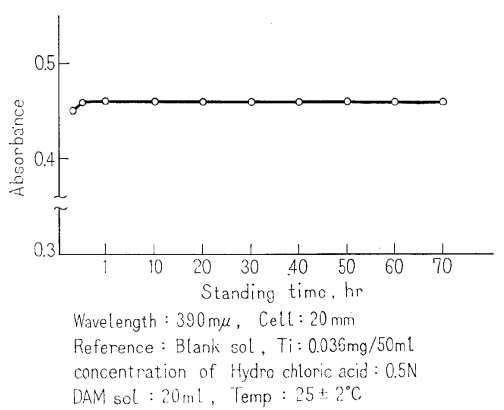

Fig. 7 Stability of Ti-DAM complex. 


\section{7 共存イオンの影響}

Table 1 に示すごとくほとんど影響しないが， Bi, W は $3 \mathrm{mg}, \mathrm{Sb} 5 \mathrm{mg}, \mathrm{Zr} 7 \mathrm{mg}$, Hf $7 \mathrm{mg}$ までは影響しな い。なおこれより多くなると, Wは正の誤差, Hf, Zr は 負の誤差を与える。少量の Nb, Ta は影響しないが多く なると沈殿する。硝酸は影響しないが過塩素酸はD A M と沈殿を生成し, リン酸は発色をおくらせる傾向があ る。フッ素が共存すると発色しなくなる。E D T A は影 響しない。したがつてマスキング剂として用いることが 可能である。アルミニウム合金中のチタンを定量する場 合, 銅, クロム等の着色イオンが共存しても, DAMの みを加えない可検溶液を対照液として測定すれば分析例 に示すごとくその影響をさけることができる。またシュ ウ酸の防害が大きく, ついでクエン酸, 酒石酸の順に影 響する。しかし Polyak ${ }^{8}$ は，二オブを酒石酸溶液に溶 解しその中のチタンを定量しているが，このようなとき は酒石酸量を常に一定にすることが必要である。なお鈴 木ら ${ }^{9)}$ は，アルミニウムは $1 \mathrm{~g}$ 以上共存しても影響がな

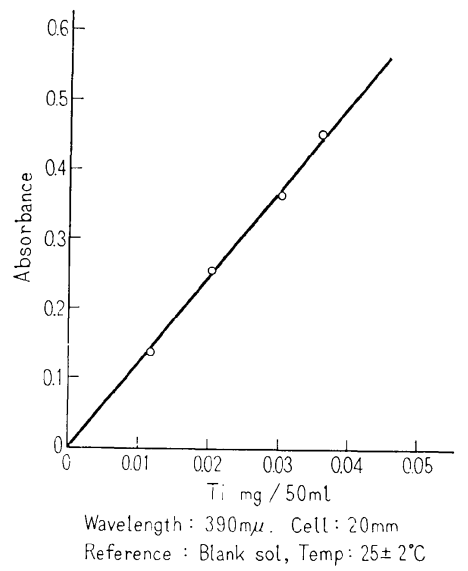

Fig. 8 Calibration curve.

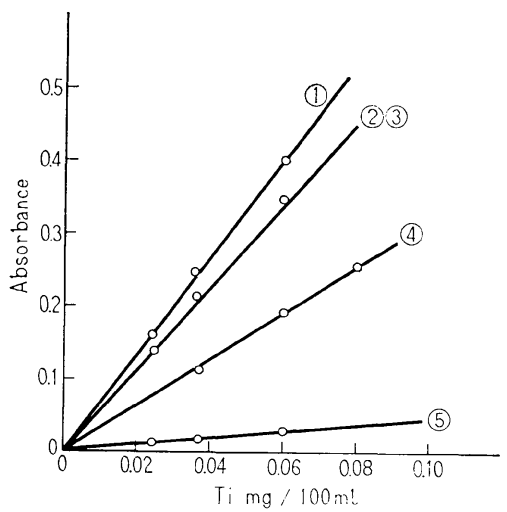

(1) : Chromotoropic acid method

(2) (3): Tiron, DAM method

(4) : Alizarin $S$ method

(5) : Hydrogen Peroxide methed

Fig. 9 Calibration curve.
いと報告している。

3.8 分 析 例

標準試料とアルミニウムおよびその合金中のチタンの 分析結果を Table 2, 3 に示す。Table 2 をみるとB.C.S. および N.B.S. の標隻值と本法による分析值とがよく一 致していることがわかる。Table 3 法試料を塩酸に溶解 し，不溶解残サのあるときはこしわけ，塩酸に可溶性の チタンと残サ灲に残存するチタンを定量した結果を示 す。Ti-Boride を添加した合金以外は分析誤差範囲内な ので考慮する必要がない。

\section{4. 結言}

D A M は発色時の酸濃度範囲が広く, 完全発色すれば 錯体は非常に安定である。他の方法と比較し優れた点 は，妨䇺元素が少なく高感度であることである。したが つて現行微量チタンの定量法としては最良の方法である と䍐われる。

本報告では，Ti-DAM 錯体の発色のおくれる原因が

Table 1 Effect of diverseions.

\begin{tabular}{|c|c|c|c|c|}
\hline \multicolumn{2}{|c|}{ Added diverse ions } & \multicolumn{3}{|c|}{$\mathrm{Ti} \quad \mathrm{mg}$} \\
\hline \multirow[t]{2}{*}{ Name } & \multirow[t]{2}{*}{$\begin{array}{c}\text { Addded } \\
\text { (mg) }\end{array}$} & Added & Found & \multirow[t]{2}{*}{ Error } \\
\hline & & 0.036 & 0.036 & \\
\hline $\begin{array}{l}\text { Ni. Cu. Cr. Mn. } \\
\text { Mo. V. Co. Fe. } \\
\text { Zn. Ca. Mg. Pb. } \\
\text { Cd. Sn. P. Be. B. } \\
\text { Ce. Li. Sr }\end{array}$ & $25 \mathrm{mg}$ & 0.036 & 0.036 & 0.000 \\
\hline K. Na & $1.0 \mathrm{~g}$ & 0.036 & 0.036 & 0.000 \\
\hline \multirow{3}{*}{ W } & $25 \mathrm{mg}$ & 0.036 & 0.051 & +0.015 \\
\hline & $5 \mathrm{mg}$ & 0.036 & 0.038 & +0.002 \\
\hline & $3 \mathrm{mg}$ & 0.036 & 0.036 & 0.000 \\
\hline \multirow{2}{*}{$\mathrm{Bi}$} & $5 \mathrm{mg}$ & - & ppt & - \\
\hline & $3 \mathrm{mg}$ & 0.036 & 0.036 & 0.000 \\
\hline \multirow{2}{*}{$\mathrm{Sb}$} & $7 \mathrm{mg}$ & - & 不溶 & - \\
\hline & $5 \mathrm{mg}$ & 0.036 & 0.036 & 0.000 \\
\hline Nb. Ta & - & - & $\mathrm{ppt}$ & - \\
\hline \multirow{3}{*}{$\mathrm{Zr}$} & $20 \mathrm{mg}$ & 0.036 & 0.015 & -0.021 \\
\hline & $8 \mathrm{mg}$ & 0.036 & $0.034 !$ & -0.002 \\
\hline & $7 \mathrm{mg}$ & 0.036 & 0.036 & 0.000 \\
\hline \multirow{4}{*}{ Hf } & $25 \mathrm{mg}$ & 0.036 & 0.010 & -0.026 \\
\hline & $10 \mathrm{mg}$ & 0.036 & 0.028 & -0.008 \\
\hline & $7 \mathrm{mg}$ & 0.036 & 0.034 & -0.002 \\
\hline & $6 \mathrm{mg}$ & 0.036 & 0.036 & 0.000 \\
\hline $\mathrm{Pt}$ & $0.3 \mathrm{mg}$ & 0.036 & 0.036 & 0.000 \\
\hline $\mathrm{Al}$ & $500 \mathrm{mg}$ & 0.036 & 0.036 & 0.000 \\
\hline
\end{tabular}


Table 2 Analytical results of standard sample.

\begin{tabular}{|c|c|c|c|c|c|}
\hline \multirow{2}{*}{ Sample name } & \multirow{2}{*}{ Composition $\%$} & \multicolumn{2}{|c|}{ Analyses of BCS } & \multicolumn{2}{|c|}{$\begin{array}{l}\text { Analyses of recommended } \\
\text { method }\end{array}$} \\
\hline & & & $\mathrm{Ti} \%$ & $\begin{array}{l}\text { Measurement } \\
\text { No. }\end{array}$ & $\mathrm{Ti} \%$ \\
\hline \multirow{3}{*}{$\begin{array}{l}\text { Al-11\% Si alloy } \\
\text { (B.C.S. No. 182/1) }\end{array}$} & \multirow{3}{*}{$\begin{array}{l}\text { Si 11.5, Cu 0.20, Fe } 0.44 \text {, } \\
\text { Mn 0.28, Mg 0.08, Ni 0.04, } \\
\text { Zn 0.10, Pb 0.05, Sn } 0.015 \text {, } \\
\text { Ca } 0.04\end{array}$} & $\bar{x}$ & 0.05 & 1 & 0.045 \\
\hline & & $\mathrm{R}$ & 0.02 & 2 & 0.045 \\
\hline & & - & 一 & $\bar{x}$ & 0.045 \\
\hline \multirow{3}{*}{$\begin{array}{l}\text { Duralumin alloy } \\
\text { (B.C.S. No. 216) }\end{array}$} & \multirow{3}{*}{$\begin{array}{l}\text { Cu 4.4, Mg 0.74, } \text { Si 0.74, } \\
\text { Mn 0.73, Fe 0.40, Zn 0.11, } \\
\text { Ni 0.06, Pb 0.05, Sb } 0.05 \text {, } \\
\text { Sn 0.05 }\end{array}$} & $\bar{x}$ & 0.10 & 1 & 0.10 \\
\hline & & $\mathrm{R}$ & 0.03 & 2 & 0.092 \\
\hline & & 一 & - & $\bar{x}$ & 0.096 \\
\hline \multirow{3}{*}{$\begin{array}{l}\text { Al-10\% Mg alloy } \\
\text { (B.C.S. No. 262) }\end{array}$} & \multirow{3}{*}{$\begin{array}{l}\text { Cu } 0.03, \mathrm{Mg} 10.57, \text { Si } 0.10, \\
\text { Fe } 0.19, \mathrm{Mn} 0.06, \mathrm{Zn} 0.05 \text {, } \\
\text { Cr } 0.06\end{array}$} & $\bar{x}$ & 0.10 & 1 & 0.095 \\
\hline & & $\mathrm{R}$ & 0.03 & 2 & 0.095 \\
\hline & & 一 & 一 & $\bar{x}$ & 0.095 \\
\hline \multirow{3}{*}{$\begin{array}{l}\text { Aluminum alloy } \\
\text { (wrought) } \\
\text { (N.B.S. } 85 \text { B) }\end{array}$} & \multirow{3}{*}{$\begin{array}{l}\mathrm{Cu} 3.99, \mathrm{Mg} 1.49, \mathrm{Mn} 0.61 \text {, } \\
\mathrm{Fe} 0.24, \text { Cr } 0.21, \text { Si } 0.18, \\
\mathrm{Ni} 0.084, \mathrm{Zn} 0.030, \mathrm{~Pb} 0.021 \text {, } \\
\mathrm{Ga} 0.019, \mathrm{~V} 0.006\end{array}$} & $\bar{x}$ & 0.022 & 1 & 0.022 \\
\hline & & $\mathrm{R}$ & 0.004 & 2 & 0.022 \\
\hline & & - & - & $\bar{x}$ & 0.022 \\
\hline
\end{tabular}

Table 3 Analytical results of Aluminum and its alloys.

\begin{tabular}{|c|c|c|c|c|}
\hline \multirow{2}{*}{ Sample name } & \multirow{2}{*}{ Composition $\%$} & \multirow{2}{*}{$\begin{array}{l}\text { Measurement } \\
\text { No. }\end{array}$} & \multicolumn{2}{|c|}{$\mathrm{Ti} \quad \%$} \\
\hline & & & Soluble in $\mathbf{H C l}$ & in residue \\
\hline $\begin{array}{l}\text { Refined aluminum } \\
\text { (99.99 up) }\end{array}$ & $\begin{array}{l}\mathrm{Si}<0.005, \quad \mathrm{Fe}<0.005, \\
\mathrm{Cu}<0.005\end{array}$ & $\begin{array}{l}1 \\
2 \\
\bar{x}\end{array}$ & $\begin{array}{l}0.0006 \\
0.0006 \\
0.0006\end{array}$ & - \\
\hline $\begin{array}{l}\text { Aluminum } \\
\text { (99.5 up) }\end{array}$ & $\begin{array}{l}\mathrm{Si}<0.2, \quad \mathrm{Fe}<0.25, \\
\mathrm{Cu}<0.02, \quad \mathrm{Mn}<0.01\end{array}$ & $\begin{array}{l}1 \\
2 \\
\bar{x}\end{array}$ & $\begin{array}{l}0.0045 \\
0.0045 \\
0.0045\end{array}$ & $\begin{array}{l}- \\
-\end{array}$ \\
\hline $\mathrm{AC} 2 \mathrm{~B}$ casting alloy & $\begin{array}{l}\mathrm{Cu} 4.0, \quad \mathrm{Si} 5.0, \quad \mathrm{Mg}<0.5, \\
\mathrm{Zn}<1.0, \mathrm{Fe}<1.0, \quad \mathrm{Mn}<0.5, \\
\mathrm{Ni}<0.3\end{array}$ & $\begin{array}{l}1 \\
2 \\
\bar{x}\end{array}$ & $\begin{array}{l}0.083 \\
0.084 \\
0.084\end{array}$ & $\begin{array}{l}0.0008 \\
0.0009 \\
0.0009\end{array}$ \\
\hline $\mathrm{Al}-\mathrm{Zn}-\mathrm{Mg}$ alloy & $\begin{array}{l}\mathrm{Si}<0.3, \quad \mathrm{Mg} 2.0, \quad \mathrm{Fe}<1.0, \\
\mathrm{Mn} 0.2, \quad \operatorname{Zn} 6.0\end{array}$ & $\begin{array}{l}1 \\
2 \\
\bar{x}\end{array}$ & $\begin{array}{l}0.067 \\
0.067 \\
0.067\end{array}$ & $\begin{array}{l}- \\
-\end{array}$ \\
\hline Aluminum alloy & B 0.01 & $\begin{array}{l}1 \\
2 \\
\bar{x}\end{array}$ & $\begin{array}{l}0.196 \\
0.195 \\
0.196\end{array}$ & $\begin{array}{l}0.020 \\
0.020 \\
0.020\end{array}$ \\
\hline (added Ti-Boride) & B 0.07 & $\begin{array}{l}1 \\
2 \\
\bar{x}\end{array}$ & $\begin{array}{l}0.160 \\
0.157 \\
0.159\end{array}$ & $\begin{array}{l}0.036 \\
0.035 \\
0.036\end{array}$ \\
\hline
\end{tabular}

塩酸濃度，DAM添加量および液温にあることを確め， 塩酸濃度を 1 N以下, D AM 1 \%溶液の添加量を最終液 量ごとに定め, 液温を20〜 $30^{\circ} \mathrm{C}$ で発色することとした。 またD A Mを稀塩酸に溶解し安定するとともに, 共存イ オンの許容量を求めた。

終りに, 本定量法の検討に際し種々助言をいただいた
同仁薬化学，今村部長に深く感謝する。

\section{文献}

1) T. C. J. Ovenston, C. A. Parker and C. G. Hatchard: Anal. Chimica. Acta., 6 (1952) 7.

(p. 40 へつうく) 
(p. 45 より)

2) J. H. Yoe and A. R. Armstrong: Anal. Chem., 19 (1947) 100.

3) 後藤, 柿田, 並木 : 日化 78 (1957) 373 .

4) M. Ziggler and O. Glemson: Z. Anal. Chem., 139 (1953) 92.

5) L. Ya. Polyak: J. Anal. Chem., USSR, 17 (1962) 205.

6) P. G. Jefery and G. R. F. C. Gregory: Analyst,
90 (1965) 177.

7) 武井, 二村, 大羽 : 分化講演要旨集 (於八幡) (1964) 5 .

8) L. Ya. Polyak: Zhurnal Analiticheskoi Khimii, 12 (1964) 1468.

9) 鈴木, 小山内：軽金属協会微量分析委員会資 料 No. 10 (1965).

10) V. N. Podchainova and A. D. Dolgorev: Zhm. Anal. Khim., 20 (1965) 1059. 